\title{
Discurso midiático e meio ambiente: análise de discursos ambientais em capas da revisa Veja
}

Considerando que o discurso consiste em um conjunto de ideias, conceitos e concepções que são (re)produzidas nas práticas sociais. Questiona-se, esta investigação, sobre os discursos ambientais: Quais são as visões e tipos de discursos apresentados no gênero textual capa de revista? Nesse sentido, objetiva-se analisar o discurso ambiental em capas da revista Veja. Para tanto, procede-se à pelo método de abordagem qualitativo, e com corpus formado por três capas da revista Veja dos últimos dez anos, escolhidas de acordo com cada tipologia discursiva ambiental de Hannigan (2009). Desse modo, observa-se que as capas analisadas apresentam um processo de produção de textos com usos de linguagens que envolvem os consumidores a formarem seus pensamentos e opiniões de acordo com a ideologia da revista, passando a contribuir para (re)produção ou (trans)formação de relações sociais com meio ambiente.

Palavras-chave: Análise do discurso; Discurso midiático; Meio ambiente; Revista Veja.

\section{Media discourse and environment: analysis of environmental discourses in covers of Veja magazine}

\begin{abstract}
Whereas the discourse consists of a set of ideas, concepts and concepts that are (re) produced in social practices. This investigation is questioned about environmental discourses: What are the views and types of discourses presented in the magazine cover textual genre? In this sense, the objective is to analyze the environmental discourse in Veja magazine covers. For that, we proceed by the qualitative approach method, and with a corpus formed by three covers of Veja magazine from the last ten years, chosen according to each Hannigan (2009) environmental discursive typology. Thus, it is observed that the analyzed covers present a process of producing texts with uses of languages that involve consumers to form their thoughts and opinions according to the magazine's ideology, starting to contribute to (re) production or (trans)formation of social relations with the environment.
\end{abstract}

Keywords: Discourse analysis; Media discourse; Environment; Veja magazine.

Topic: Ensinos Multidisciplinares

Reviewed anonymously in the process of blind peer.
Received: $19 / 04 / 2021$

Approved: 20/07/2021
Lucas Andrade de Morais 10

Universidade do Estado do Rio Grande do Norte, Brasil

http://lattes.cnpq.br/4304836710800316

http://orcid.org/0000-0003-4443-2393

lucasmorais7@gmail.com
Referencing this:

MORAIS, L. A.. Discurso midiático e meio ambiente: análise de discursos ambientais em capas da revisa Veja. Educationis, v.9, n.2 p.79-89, 2021. DOI: http://doi.org/10.6008/CBPC23183047.2021.002.0010 


\section{INTRODUÇÃO}

A discussão sobre o meio ambiente tem ganhado um espaço significativo em meios de comunicações sociais, cujo objetivo seria buscar possíveis soluções em nível planetário para problemas ambientais que afetam diretamente a vida da humanidade. Por isso, é notável a eminência de discursos ambientais em grandes jornais, revistas, mídias digitais e demais veículos de comunicações.

O discurso como uma prática social é um importante objeto de investigação, e pensando assim, a presente pesquisa se propôs investigar se e como a questão ambiental é abordada em capas de revistas impressas.

Nessa mesma proposta temática de investigação tem-se na literatura as discussões de Silva (2010), que faz uma leitura de imagens da mídia, focando nas contribuições da educação ambiental para a formação de professores; Pimenta et al. (2010) fazem um levantamento da questão ambiental em uma perspectiva de estudo da linguagem geográficas em capas da revista Veja de 1968 a 2008; E mais recente, Garré et al. (2017) com uma análise do discurso foucaultiana sobre a crise ambiental na mídia impressa (revista Veja).

A escolha pela análise em capas da revista Veja, voltada para temas ambientais, deu-se por ser um dos periódicos jornalísticos mais vendidos no país, atingindo um grande público de leitores e observadores.

O problema orientador deste trabalho foi compreender: Que discursos a mídia impressa tem construído recentemente sobre a questão ambiental? Partindo dessa pergunta central, os objetivos principais que nortearam a investigação foram: Examinar como uma revista de generalidades constrói o discurso ambiental para os seus leitores.

Para tanto, o presente artigo, realiza uma análise (teórico-prática) específica sobre o discurso presente nas capas das revistas que se referem ao meio ambiente, observando a utilização de textos verbais e não verbais, realizando intepretações para o discurso, visando compreender qual a mensagem e o que se deseja alcançar com o discurso empregado.

\section{METODOLOGIA}

O método de abordagem utilizado foi o qualitativo com fins descritivos, cujos dados foram obtidos através de um levantamento documental de capas de revistas com temáticas sobre o meio ambiente.

O corpus da pesquisa constituiu-se por capas da revista Veja dos últimos 10 anos, escolhidas três capas de acordo com cada tipologia discursiva ambiental de Hannigan (2009). A escolha do corpus ocorreu pelo poder de circulação da revista no país, e por se tratar de um periódico semanal, seu público-alvo é constituído de classes sociais mais favorecidas economicamente (geralmente dominante), refletindo, a priori, sua orientação ideológica tendente a defender o capital (econômico). Muito embora as classes menos favorecidas não tenham acesso ao conteúdo completo da revista Veja, ficam mais exposto aos discursos das capas (em bancas de jornais), a construção dela tende a influenciar politicamente também essas camadas.

$\mathrm{O}$ acesso ao corpus ocorreu por meio do acervo digital da revista $\mathrm{Veja}^{1}$, que oferece gratuitamente o

${ }^{1}$ https://acervo.veja.abril.com.br/index.html\#/search 
acesso à todas as capas de suas publicações. Assim, foram encontradas nos últimos dez anos, 9 (nove) capas que mencionavam a temática ambiental, sendo escolhidas as capas das Edições 2031 (2007), 2130ạ (2009) e 2151 (2010).

\section{RESULTADOS E DISCUSSÃO}

\section{Análise do Discurso}

As práticas sociais são marcadas pelo uso da linguagem por meio de discurso, que podem representar o conhecimento, as relações sociais e a identidade social (FAIRCLOUGH, 2016). Um discurso se constitui “[...] como ocorrência linguística falada ou escrita, de qualquer extensão, dotada de unidade sociocomunicativa, semântica e formal” (VAL, 1999).

O gênero discursivo passou a ser interesse de muitos estudiosos que buscam investigar sobre relações de poder e a formação de ideologia por trás dos textos. Assim, a Análise do Discurso (AD), enquanto disciplina, surgiu a partir da década de 60 como resultado das convergências de correntes, práticas e pressupostos de estudos da retórica, hermenêutica e filologia que buscavam uma significação social além do texto em si (PAULIUKONIS et al., 2012).

As atividades discursivas tornaram-se objetos de observações e estudos e suas construções sofreram influências de diversas teorias e campos do saber. Os maiores influenciadores para os estudos discursivos foram: a Escola Francesa da Análise do Discurso Francesa - ADF, cujo autor mais representativo foi o francês Michel Pêcheux (1968) e a Análise Crítica do Discurso - ACD (anglo-saxã), com representatividade e influência do linguista britânico Norman Fairclough (1941), de modo geral:

A análise de discurso se faz entre a linguística e as ciências sociais, interrogando a linguística que pensa a linguagem mas exclui o que é histórico-social e interrogando as ciências sociais na medida em que estas não consideram a linguagem em sua materialidade. A análise de discurso vai colocar questões da linguística para a linguística assim como vai colocar questões das ciências sociais para as ciências sociais, interrogando-as, pois, no campo mesmo em que elas se constituem. Por seu lado, a análise de discurso não é uma resposta a essas questões. Ela vai mostrar que para respondê-las é necessário deslocar-se de terreno constituindo outra região teórica em que o sócio-histórico e o linguístico se relacionam de maneira constitutiva e não periférica. (ORLANDI, 2006)

$\mathrm{Na}$ Análise do Discurso o sujeito que produz um discurso busca gerar um efeito de sentido para o seu destinatário (interlocutor), que por meio dos elementos textuais e/ou visuais do processo discursivo significará pelos aspectos materiais e ideológicos. Porém, é preciso deixar claro que o objetivo da análise do discurso não é analisar a existência de uma verdade, mas uma verossimilhança, ou seja, uma fazer crer (encenação da verdade).

O campo da Análise do Discurso é caracterizado por uma múltiplas vertentes e teorias de análises de discursos que divergem entre si, por meio de suas abordagens teóricas e procedimentos metodológicos, uma delas é a Teoria Semiolinguística do Discurso (TS).

A TS é proposta pelo linguista francês Patrick Charaudeau em meado da década de 1980, objetivando analisar o funcionamento da argumentação no discurso científico de pesquisadores da área de linguística, fundamentou sua teoria em bases comunicacionais e interativas entre os fatos da linguagem e os fenômenos 
psicológicos ou sociais, em que o sentido será resultante de operações enunciativo-discursivas de entidades subjetivas do discurso (PAULIUKONIS et al., 2012; CORRÊA-ROSADO, 2014). Logo essa teoria de natureza psico-sócio-comunicativa é também chamada de semiodiscursiva ou de semiolinguística de análise do discurso, pois:

[...] uma análise semiolinguística do discurso é semiótica pelo fato de que se interessa por um objeto que só se constitui em uma intertextualidade. Esta última depende dos sujeitos da linguagem, que procuram extrair dela possíveis significantes. Diremos também que uma análise semiolinguística do discurso é linguística pelo fato de que o instrumento que utiliza para interrogar esse objeto é construído ao fim de um trabalho de conceituação estrutural dos fatos linguageiros. (CHARAUDEAU, 2008)

Assim um enunciado seria uma combinação de componentes verbais e os situacionais (não verbais), que no processo de análise da imagem do "eu" (enunciador projeta de si) em seu discurso pode significar o mundo para o outros, uma vez que:

A constituição dessa imagem pode ser visualizada por meio de um duplo recorte: o da enunciação ampliada - em que se faz o exame do contexto, incluindo os protagonistas e parceiros e as circunstâncias de produção do ato comunicativo - e o da enunciação restrita - com o enfoque de procedimentos linguísticos que se constituem como marcas sinalizadoras (pistas) na construção de uma imagem ou de um ethos legitimador da fala enunciada. (PAULIUKONIS et al., 2012)

Portanto, para a TS todo ato de comunicação social é uma encenação que pressupõe a existência de um contrato social, comportando quatro protagonistas "[...] sendo dois situacionais, externos e dois discursivos, internos. Os sujeitos "externos" são o EUc (eu-comunicante) e o TUi (tu-interpretante) e os sujeitos "internos", o EUe (eu-enunciador) e o TUd (tu-destinatário)" (CHARAUDEAU, 2001).

A partir disso ocorre o processo de "semiotização do mundo" (CHARAUDEAU, 2008) a partir de dois pontos, quais sejam: 1) Processo de transformação - nesse âmbito ocorre as ações e projetos do sujeito comunicante (instância de produção da informação) de modo a transformar o 'mundo a significar' (mundo a descrever e a comentar) em 'mundo significado' (mundo descrito e comentado); 2) Processo de Transação (base da construção do contrato de comunicação) - nessa etapa o processo de transformação (mundo significado) é a base de uma troca entre o sujeito comunicante (enunciador do ato) com o sujeito interpretante ou destinatário (instância de recepção - interpretação).

Assim, o processo de transação, na situação da revista Veja, ocorre na fase da compra (ou leitura) do material, em que a informação (mundo significado) recepcionada pelo leitor é a fornecida pelo jornalista, estando sujeito a interpretar um fato pela ótica do que é mostrado pelas palavras e imagens apresentadas pela revista (que podem ou não coincidir com a realidade).

O processo discursivo ocorre por meio do caráter semântico-discursivo das relações intersubjetivas, contexto social, cultural e histórico e pelos aspectos ideológicos, posto que "[...] ato de linguagem significa não somente pela sua configuração semiológica visível, mas também pelos saberes que são acionados pelos sujeitos durante os processos de produção e interpretação desse ato" (CORRÊA-ROSADO, 2014).

Nesta perspectiva, a escolha da TS como forma de análise do discurso ambiental das capas da revista Veja se compreendeu por essa teoria se destaca dentre as teorias de Análise do Discurso, pois possui um grande potencial de analisar diferentes discursos sociais (político, midiático, publicitário e literário) em 
diferentes circunstâncias, com ênfase nos sujeitos da linguagem e de suas intencionalidades.

\section{O meio ambiente, a mídia e o discurso ambiental}

A temática ambiental vem ganhando espaço na imprensa brasileira e internacional, isso acontece por causa das devastações das florestas (exemplo as queimadas ocorridas na Amazônia) e por causa do aquecimento global, mas ainda faltam profissionais com formação e conhecimentos adequados para a cobertura da temática ambiental.

É importante ressalvar que as funções do jornalismo ambiental são: 1) informar o cidadão sobre seus hábitos e possíveis consequências; 2) pedagógica que explica as causas e também as soluções para os problemas em questão e 3) política ao abordar coberturas que demonstrem a ação de cidadãos e instituições que contribuem para o agravamento da crise ambiental, seja por interesse privados ou pela omissão do poder público (BUENO, 2007).

Nesse sentido, pela compreensão sobre o que constitui o meio ambiente e as funções do jornalismo/comunicação ambiental é possível observar e detectar as produções de notícias ambientais no país, que tem coberturas limitadas e moldadas pelos que detém o poder e controle sobre as mídias e seus materiais, uma vez que geralmente as mídias são patrocinada por marcas multinacionais ou grandes empresas que geralmente se envolvem em danos ambientais (exemplo é o caso Samarco versus MarianaMG), o que resulta na omissão da cobertura, parcialidade na notícia ou utilizado como ferramenta de marketing das empresas.

Mídias conservadoras e comunicadores desavisados tendem, muitas vezes, a ignorar as raízes do jornalismo ambiental, sua disposição irrecusável para a mobilização e para o despertar de consciências, tentando torná-lo refém de ações mercadológicas ou empresariais e interesses políticos. Confundem jornalismo ambiental com marketing verde ou ecopropaganda, termos e práticas que se situam não apenas em campos conceituais e epistemológicos distintos, mas que estão atrelados a compromissos de outra ordem. (BUENO, 2007)

Os discursos midiáticos das questões ambientais têm focalizado na construção de textos moldurados com: a) metáforas; b) frases feitas ou expressões repetidas por celebridade, retratos e imagens visuais; c) raízes (análise causal); d) consequências e e) apelos de princípios (argumentos morais) construindo um tipo simbólico que serão decodificados pelos consumidores (leitores, ouvintes) das notícias (HANNIGAN, 2009).

Por isso, a comunicação ambiental, assim como outras, é um meio de arriscar a se aventurar por um local desconhecido, posto que nunca se saberá como os consumidores irão entender a mensagem que será passada, não estando isenta da incompreensão ou negação, muito menos de aceitar passivamente as molduras do discurso ambiental que é passado pela mídia.

\section{Análise do Discurso Ambiental}

O discurso ambiental se configura como um conjunto de ideias, conceitos e concepções que são produzidos, reproduzidos e transformados em práticas e ações que (re)significam e (re)interpretam o mundo e suas relações com os recursos naturais (HAJER, 1995). 
Diversos são os autores que trazem tipologias para análise do discurso ambiental, dentre eles temse Herndl et al. (1996) que apresentam um "modelo retórico para o discurso ambiental" que é dividido em três tipos de discursos: regulatório, científico e o poético (Figura 1).

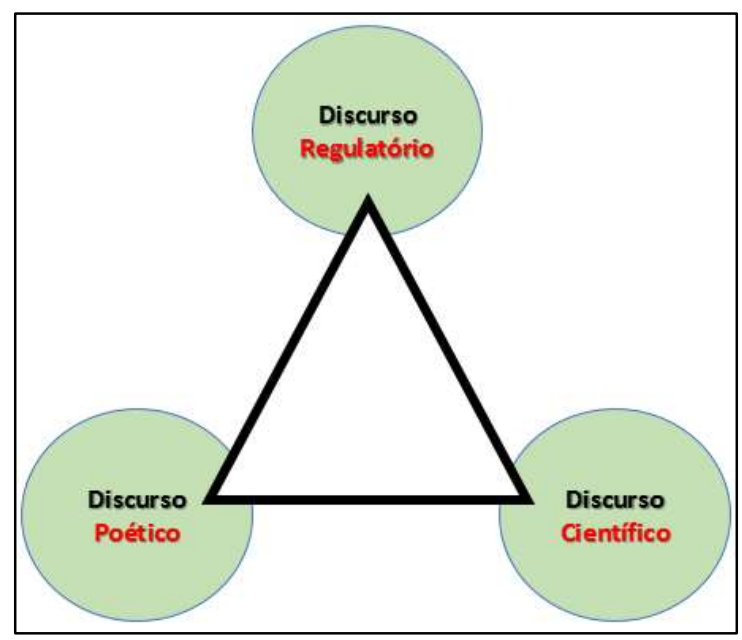

Figura 1: Modelo retórico para o discurso ambiental.

Na Análise do Discurso Ambiental, de Herndl et al. (1996), no discurso regulatório a natureza é compreendida como um recurso, sendo um discurso disseminado por instituições que decidem e estabelecem políticas ambientais. No discurso científico a natureza é compreendida como objeto de conhecimento, cujos dados técnicos e especialistas oriundos desses discursos influenciam as decisões dos formuladores de políticas. Por fim, o discurso poético é o formulado pela literatura da/sobre a natureza que enfatiza sua beleza. Esses três tipos de discursos ambientais não são exclusivos, podendo, portanto, haver a presença de mais de um ou até os três em um texto, sendo possível investigar as "tendências dominantes" em um gênero textual com base discursiva ambiental.

Esta pesquisa adotará a tipologia de Análise do Discurso Ambiental de Hannigan (2009), que se aproxima de algumas características da tipologia dos autores Herndl et al. (1996), sendo os principais discursos ambientais no século XX caracterizado em três tipos de discursivo: Arcádio, Ecossistema e Justiça.

O discurso arcádico surge na década de 70 com o movimento ambiental moderno, atuantes na chamada vanguarda do ambientalismo (movimento de volta à natureza), cuja percepção e visão da natureza sem preço de valor estético e espiritual (HANNIGAN, 2009).

O discurso do ecossistema é centrado nas noções de "ecologia" e "ecossistema", oriundas das ciências biológicas, aproximando do "discurso científico" (HERNDL et al., 1996), para essa linha discursiva as interferências humanas nas comunidades bióticas perturbam o equilíbrio da natureza (HANNIGAN, 2009).

Por fim, o discurso de justiça ambiental, advindos nos anos 80 , tem em suas formações discursivas argumentos em prol dos direitos civis em que todos os cidadãos têm um direito básico de vive e trabalhar num ambiente saudável (HANNIGAN, 2009).

A tipologia de discursos ambientais de Hannigan não devem ser pensados de modo estático ou exclusivo, mas de modo dialético e complexo. 


\section{Discursos ambientais em capas da revista Veja}

As capas de revistas constituem gênero textual do tipo sincrético ou multimodal, pois em sua formação apresentam elementos verbais e não verbais, sendo, portanto, necessário a leitura de ambos os elementos para construir a ideologia discursiva da mensagem para os leitores.

As capas de revistas são equivalentes as embalagens de produtos, ou seja, são portas de entradas das notícias. Esse gênero tem o poder de influenciar a formação (antecipada) de opinião de leitores sobre os conteúdos, antes mesmos de ter acesso a integralidade de notícias, repostagens e artigos, anunciados pelas revistas. É importante lembrar que muitos grupos sociais de leitores se restringem apenas a exposição signica das capas para formularem sua opinião sobre determinado assunto.

Nessa investigação partiu-se do estudo das capas da revista Veja com abordagem ambiental realizadas nos últimos dez anos. Na pesquisa foram encontradas nove capas com discursos ambientais, dessas somente três capas são de números semanais e o restante são edições especiais com ênfase em temáticas ambientais. Nessa pesquisa serão analisadas apenas três capas que contemplam as tipologias discursivas de Hannigan (2009).

Por se tratar de uma produção do campo midiático, em contraponto a um possível "jornalismo ambiental", é preciso compreender as notícas quanto ao aspecto formal e ao de conteúdo (BAKHTIN, 2003). Assim, a primeira analise é a capa da revista Veja da edição no 2031, de 24/10/2007 (Fig. 2), com o tema "Salvar a terra - como essa idéia triunfou".

A capa aprensenta um discurso ambiental em forma de um objetivo, que remete ao leitor, os enunciados verbais (elementos textuais) torna sentido com os não verbais (não-textuais-imagem) ao apresentar uma mulher, sua filha e uma bicicleta. O sentido da capa busca 'implantar' uma ideia de mudanças de hábitos nos leitores para 'salvar' a terra, e para isso apresenta algumas medidas exemplificativa ao longo da imagem como o ponto de ligação na cabeça da mulher identificada pela 'consciência ambiental', ponto inicial para mudança de hábito. Apresentam atitudes, acções ou medidas que a mulher 'adota' (representa) para não agravar o consumo dos recursos naturais no planeta, a exemplo do uso de 'camista de fibra reciclada', 'sacola de fibra natural', 'Cantil (para evitar garrafas PETs)', 'Calça de algodão feita a mão' e 'sandálias com sola de pneu reciclado' e consumo de 'alimentos organicos' como forma de evitar o aumento de contaminação por agrotóxicos que geram danos à saúde humana, animal e ao meio ambiente.

Na imagem é possível observar que a mulher usa como meio de transporte uma 'bicicleta (zero CO2)'" como forma de evitar os gases que contribuem para o aquecimento global e efeito estufa.

A revista ainda sugere que as novas famílias tenham 'filho único', ou seja, essa geração teria que reduzir o crescimento populacional, entendendo que quanto mais pessoas no planeta, maior ser a utilização dos recursos naturais. Ainda sugere que os pais adotem o uso de 'Falda de pano' em substituição da falda descartável, por ser um produto não reciclável e que causa impacto negativo ao meio ambiente.

A imagem reprensenta o planeta em forma de balão, segurado pela criança, como uma forma de tratar os discursos das sustentabilidade ambiental, em que as ações devam garantir um meio ambiente sádio 
e equilibrado para as presentes e futuras gerações, assim, salvar a terra para filhos, netos e descendentes, um projeto de futuro para que se possam usufruir de um mundo ecologicamente equilibrado e sustentável.

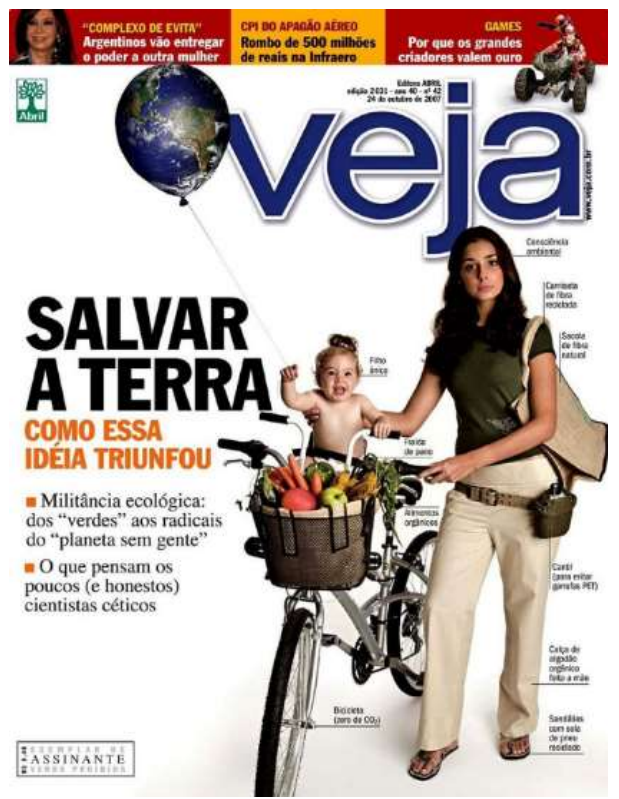

Figura 2: 'Salvar a Terra'. Fonte: Veja, Edição 2031, 24/10/2007.

A capa da revista apresenta duas informações textuais fortalecem o discurso ambiental em prol da mudança de hábitos para salvar a terra. No enunciado verbal "Militância ecológica: dos 'verdes' aos radicais do 'planeta sem gente"' a intenção seria gerar um enfraquecimento no discurso ambiental dos movimentos conservacionistas, botando em dúvida o "verde" desses movimentos sociais e criando uma distopia dos movimentos radicais.

O outro enunciado verbal 'O que pensam os poucos (e honestos) cientistas céticos' tem uma função de validação científica dos argumentos de 'salvar a terra', o que propícia influenciar os leitores a 'comprarem' a ideia da revista, é uma tentativa de 'manipulação', pois não é o leitor (ou outro orgão ou instituição) quem escolhe o que são os cientistas 'honestos', mas a revista que determina e quantifica ao ponto de afirmar que são poucos.

Nesse sentido, o discurso ambiental contido na capa da revista Veja (Edição no 2031) tem uma forte tendência de dominação para o discurso de justiça ambiental (HANNIGAN, 2009), por buscar modos para sustentábilidade do planeta por um direito ao meio ambiente para as presentes e futuras gerações.

A segunda análise da capa da revista Veja, é da edição no 2151 de 09/02/2010 (Figura 3), com o tema "Por que chove tanto".

A capa da revista apresenta elementos visuais e não-visuais. Nos elementos visuais a capa provoca o leitor com uma indagação: 'Por que chove tanto?', e em sêquencia apresenta uma possível resposta para o leitor do que 'seria a causa do dilúvio que há mais de 40 dias castiga o Sul e o Sudeste do Brasil' ligando a 'Uma rara combinação de fatores atmosféricos'.

Os elementos não verbais são apresentados por um guarda chuva tentando abrigar uma cidade dos raios e chuvas. 0 título da capa busca roteirizar/justificar o problema da imagem, que aumenta o apelo visual (semiótico) para chamar a atenção do leitor. 


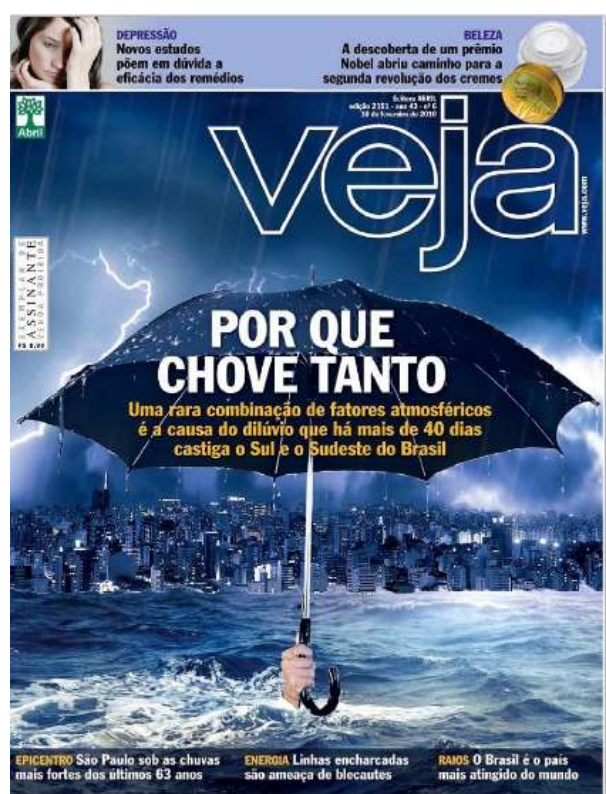

Figura 3: 'Por que chove tanto'. Fonte: Veja, Edição 2151, 09/02/2010.

Além dos elementos centrais (verbais e não verbais) da capa, é interessante observar que a força dos enunciados (elementos textuais) contidos na nota de rodapé tem uma função secundária e complementar que ajuda a reforçar a causa da pergunta central ('Por que chove tanto'), com dados e informações estátisticas e cientificas, como: 'EPICENTRO: São Paulo sob as chumas mais fortes dos últimos 63 anos', 'ENERGIA: Linhas encharcadas são ameaças de blecautes' e 'RAIOS: O Brasil é o país mais atingido do mundo', esses enunciados buscam atribuir, por meio da conteúdo científico, aos fenomenos naturais a culpa pelas catastrofes que aconteceram em cidades das Regiões Sul e Sudeste do país.

É possível compreender que a revista vai buscar 'influenciar' o leitor que os desastres, acidentes e catastrofes que 'castiga' as cidades são oriundos da 'rara combinação de efeitos atmosféricos' e não de problemas de gestão pública ambiental dessas cidades, de ocupações desordenadas e da ausência de planejamento ambiental adequado. Ao culpar a natureza (com apoio aos dados científicos) a revista tem a intenção de minimizar a responsabilidade de empresas de fornecimento de energia, empresas de construção civil, revoltas populares e também possíveis questionamentos e responsabilização dos poderes públicos para a efetivação do direito à cidade (meio ambiente urbano) ecologicamente equilibrado

O discurso ambiental contido na capa da revista Veja (Edição 2151) tem uma forte tendência de dominação para o discurso do ecossistema (HANNIGAN, 2009), pois usa da ciência e dos fenomenos naturais para "culpabilizar" problemas de gestão pública ambiental. A terceira, e última, análise da capa da revista Veja, é a edição especial no 2130A, de 16/09/2009 (Figura 3), com o tema "Amazônia - O fator humano".

Nos elementos visuais, a capa da revista apresenta a imagem de uma criança indígena e um maquinho em seu ombro, enquanto que os elementos não-visuais (textuais) apesentam o tema central da edição doo períodico: "Amazônia", e como temáticas específicas aborda: "O fator humano" em que faz um clamor sentimentalista ao leitor ao afirmar que "O destino da Amazônia está atrelado à vida de seus 25 milhões de habitantes".

Os enunciados das notas de rodapé buscam sensibilizar os leitores sobre a necessidade da 
preservação e conservação da vida na Amazônia, apresentando uma visão de natureza de valor estético e espiritual, usando um discurso e simbologias de fontes sentimentalistas e culturais típicas dos movimentos de volta à natureza.

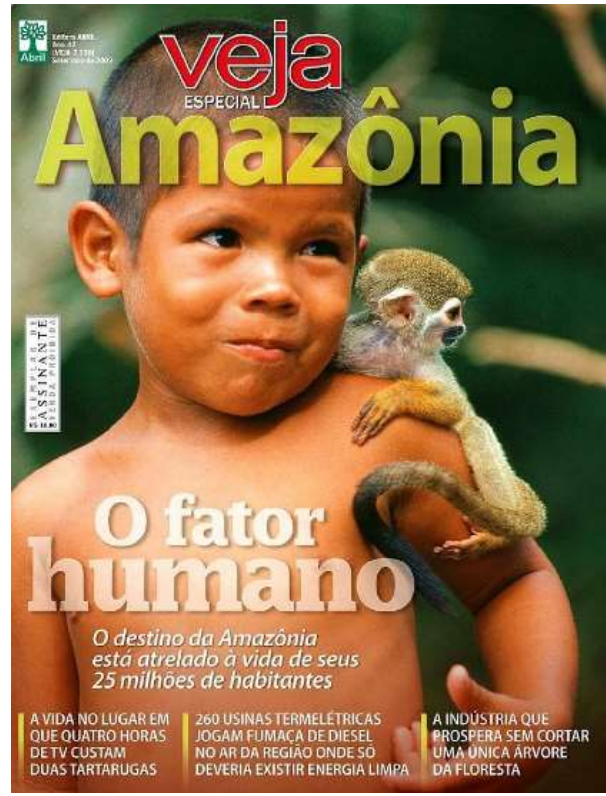

Figura 3: ‘Amazônia’. Fonte: Veja, Edição 2130A, 16/09/2009.

A revista procura apresentar ao leitor os problemas da "colonização" amazônica e como isso afeta a perpetuação das culturas indigenas, enfatizando as belezas e riquezas ambientais e culturais da região, denotando um discurso ambiental com forte tendência de dominação para o discurso do arcádico (HANNIGAN, 2009).

Em todos os discursos ambientais promovidos nas três capas da revista Veja a produção de textos verbais e não verbais tem características de valores, posições políticas, desejos e crenças que influeciam na forma com os leitores podem interpretar os fatos ocorridos, uma vez que todo signo possui um viés “idológico" (BAKHTIN, 2003).

\section{CONCLUSÕES}

Ao fim das análises, faz-se mister destacar que nas revistas existem um forte apelo midiático voltado para a questão e crise ambiental planetária. Para explicação desse problema é possível perceber a presença de inúmeros discursos ambientais sejam arcádico, ecossistema ou da justiça, em que a mídia vem buscando, a cada momento, influenciar chamando atenção dos leitores e ouvintes para a problemáticas ambientais.

Uma das abordagem utilizadas para proferir um discurso ambiental é por meio do gênero textual capa de revista. A capa se constituem, geralmente, uma embalagem que atrai o leitor. A sua constituição normalmente se compõe de imagens e textos para fisgar os olhares dos leitores.

Nas análises das capas das revistas Veja foi possível inferir que o discurso ambiental surge por meio das imagens que se construíram como uma opinião (ideologia) da própria revista, ou seja, o comunicante, passa a ser enunciador ao repassar a ideologia da revista em que trabalha.

Portanto, a análise além das capas se faz necessário e propícia para os leitores a compreensão sobre 
o mundo em que se situam e detectar o discurso por trás do discurso da capa da revista Veja. Que pode ser usado como recurso educativo e informativo das questões ambientais, em diferentes locais, setores, organizações e situações.

\section{REFERÊNCIAS}

BAKHTIN, M.. Estética da criação verbal. 4 ed. São Paulo: Martins fontes, 2003.

BUENO, W. C.. Jornalismo Ambiental: explorando além do conceito. Desenvolvimento e Meio Ambiente, v.15, 2007. DOI: http://dx.doi.org/10.5380/dma.v15i0.11897

CHARAUDEAU, P.. Linguagem e discurso: modos de organização. São Paulo: Contexto, 2008.

CHARAUDEAU, P.. Uma teoria dos sujeitos da linguagem. In: MARI, H. et al. Análise do discurso: fundamentos e práticas. Belo Horizonte: Núcleo de Análise do Discurso FALE/UFMG, 2001

CORRÊA-ROSADO, L. C.. Teoria semiolinguística: alguns pressupostos. Revista Memento, Belo Horizonte, v.05, n.2, p.1-18, 2014, 2014.

FAIRCLOUGH, N.. Discurso e mudança social. 2 ed. Brasília: Universidade de Brasília, 2016.

GARRÉ, B. H.; HENNING, P. C.. Discurso da crise ambiental na mídia impressa. Educação em Revista, Belo Horizonte, v.33, e138587, 2017.

HANNIGAN, J.. Sociologia ambiental. Petrópolis: Vozes,
2009.

HERNDL, C. G.; BROWN, S. C.. Introduction. In: HERNDL, C. G.; BROWN, S. C.. Green Culture: Environmental Rhetoric in Contemporary America. Madison: University of Wisconsin Press, 1996.

ORLANDI, E.. Análise de discurso. In: ORLANDI, E.; LAGAZZIRODRIGUES, S.. Discurso e textualidade. Campinas: Pontes, 2006.

PAULIUKONIS, M. A. L.; GOUVÊA, L. H. M.. Um texto como discurso: uma visão semiolinguística. Revista do Programa de Pós-Graduação em Letras da Universidade de Passo Fundo, v.8, n.1, p.49-70, 2012.

PIMENTA, T. A. S.; FERRAZ, C. B. O.. A questão ambiental e as capas da revista Veja. Revista GEOMAE: Geografia, Meio Ambiente e Ensino, v.01, n.01, p.29-45, 2010.

SILVA, R. L. F.. Leitura de imagens da mídia e educação ambiental: contribuições para a formação de professores. Educação em Revista, Belo Horizonte, v.26, n.02, p.277-298, 2010.

VAL, M. G. C.. Redação e textualidade. 2 ed. São Paulo: Martins Fontes, 1999.

A CBPC - Companhia Brasileira de Produção Científica (CNPJ: 11.221.422/0001-03) detém os direitos materiais desta publicação. Os direitos referem-se à publicação do trabalho em qualquer parte do mundo, incluindo os direitos às renovações, expansões e disseminações da contribuição, bem como outros direitos subsidiários. Todos os trabalhos publicados eletronicamente poderão posteriormente ser publicados em coletâneas impressas sob coordenação da Sustenere Publishing, da Companhia Brasileira de Produção Científica e seus parceiros autorizados. Os (as) autores (as) preservam os direitos autorais, mas não têm permissão para a publicação da contribuição em outro meio, impresso ou digital, em português ou em tradução. 